\title{
Gluteus medius kinesio-taping: the effect on torso-pelvic separation, ball flight distance and accuracy during the golf swing
}

\author{
B Pearce, ${ }^{1}$ MSc (Physiotherapy); B Olivier, ${ }^{1}$ PhD; S Mtshali, ${ }^{1}$ MSc \\ (Physiotherapy); P J Becker, ${ }^{2} \mathrm{PhD}$ \\ ${ }^{1}$ Physiotherapy Department, Faculty of Health Sciences, University of the \\ Witwatersrand, Johannesburg, Gauteng, South Africa \\ ${ }^{2}$ Biostatistics Unit, South African Medical Research Council, Pretoria, \\ Gauteng, South Africa
}

Corresponding author: B Olivier (benita.olivier@wits.ac.za)

Background. The kinesio-taping method, which is becoming increasingly popular, may provide support and stability to joints and muscles without inhibiting range of motion.

Objective. The aim of the study was to determine the effect of kinesio-taping of the gluteus medius muscle on $\mathrm{x}$-factor (torsopelvic separation), ball flight distance and accuracy (smash factor ratio). A specific aim was to determine whether a correlation exists between hip abduction strength and $\mathrm{x}$-factor, ball distance and accuracy.

Methods. This study is a one group pretest-posttest quasiexperimental design which took place at a golf facility. Twentynine amateur golfers with handicap of scratch \pm 2 , who were between the ages of 18- and 25-years, participated in this study. Biomechanical outcomes were recorded with and without kinesio-tape applied on the gluteus medius muscle of the trail leg. Biomechanical golf swing analysis with the iClub ${ }^{\text {TM }}$ Body Motion System determined the $\mathrm{x}$-factor at the top of the backswing. Ball flight distance and accuracy were measured with FlightScope ${ }^{\circledast}$ and dominant hip abduction strength was measured with the MicroFET Hand-held Dynamometer.

Results. Kinesio-tape is effective in improving the relative hip abduction strength $(\mathrm{p}<0.001)$, although the effect size was small (Cohen's $d=0.24$ ). With regard to the biomechanical outcome measures, namely $x$-factor $(p=0.28)$, ball flight distance $(p=0.53)$ and accuracy $(\mathrm{p}=0.1)$, there was no significant improvement. Conclusion: Even though the relative hip abduction strength was improved, there was no effect on golf swing biomechanics. This can be explained due to the fact that $\mathrm{x}$-factor, ball flight distance and accuracy are dependent on a combination of body movements to produce the golf swing.

Keywords. Golf, X-factor, pelvic stability, taping

S Afr J Sports Med 2015;27(4):97-101. DOI:10.17159/2078-516X/2015/ v27i4a422

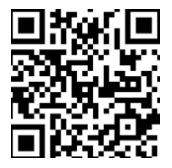

The goal that the professional, amateur and social golfer strives to achieve is maximum driving performance off the tee-box and an accurate trajectory. To best accomplish this, the club head should be travelling at maximum speed at the point of impact between the club head and the ball. ${ }^{[1]}$ The modern golf swing encourages limited lumbo-pelvic rotation during the back swing resulting in a relative increase in upper trunk rotation. The term used to describe this is the "x-factor". The $\mathrm{x}$-factor is determined at the top of the backswing and a greater $\mathrm{x}$-factor is thought to facilitate high club head speed at impact. This is based on the movement pattern naturally occurring within muscle namely the "stretch-shorten cycle". ${ }^{[2]}$ Increased torsopelvic separation creates an increase in stored energy, resulting in an increase in power build-up for a more forceful downswing. ${ }^{\left[{ }^{[3]}\right.}$ This cycle utilises a muscle's elastic and reactive properties to create a maximal force production, stimulating the joint proprioceptors to facilitate an increase in muscle recruitment. ${ }^{[4]}$

The modern golf swing is a complex, coordinated movement of the whole body in order to create power to propel the golf ball a great distance while at the same time achieving an accurate trajectory. ${ }^{[5]}$ The backswing functions to stretch the appropriate joints and muscles and position the body and the club head so that the golfer can perform the downswing with power and accuracy. ${ }^{[6]}$ The generation of work in the golf swing comes primarily from the spine and hips, generating $69 \%$ of the total body work, with the majority of work done by the trail hip. ${ }^{[7]}$ The limited lumbo-pelvic rotation required is attributed to the stabilisers within the pelvis, including the gluteal muscles and short lateral rotators of the trail hip, acting eccentrically at the top of the back swing. Gluteus medius activity increases with isometric, closed chain, rotational forces, all of which form components of the golf swing. ${ }^{[8]}$ This lateral stability, contributed to by the gluteus medius, limits the lumbo-pelvic rotation in the backswing allowing an increased upper torso turn. ${ }^{[9]}$ This results in an increased $\mathrm{x}$-factor, creating a store of potential energy in the torso to be utilised in the downswing. Transfer of power from the club to the ball enhances club head and ball speed, thus distance and accuracy. ${ }^{[3]}$

Sports taping is a muscle facilitation technique widely used in sport and rehabilitation for the prevention of injury and the improvement of muscle function. ${ }^{[10]}$ The kinesio-taping (KT) method, which is becoming increasingly popular, claims to provide support and stability to joints and muscles while at the same time aiding in pain free range of motion. ${ }^{[10]}$ Depending on how the KT is applied to the skin, various benefits were proposed, including alignment of fascia, stimulation according to the position of tape on the skin and the provision of specific sensory stimulation to the tissues in order to assist or limit movement. ${ }^{[10]}$

Smooth muscle exists within the fascia and is innervated by intrafascial nerves enabling the fascia to actively contract. ${ }^{[11]}$ It can thus be postulated that the KT's stimulation of the fascia may activate the smooth muscle within it to contract and activate the muscle it envelopes. The skin can be stretched and stimulated, activating the cutaneous mechanoreceptors which signal information about joint motion and position sense. The KT's application on the skin may contribute to proprioception by means of the abovementioned mechanism. There is not much research on the ability of the KT to increase muscle force output, and the clinical benefits of its application remain unclear. ${ }^{[12]} \mathrm{A}$ recent systematic review reports little high-quality evidence to support the efficacy of the KT. ${ }^{[12]}$ Another systematic review assessing the effectiveness of the KT concluded similarly that there was no positive effect in the KT intervention group versus the placebo group when testing quadriceps muscle strength. ${ }^{[13]}$ There is limited research on how gluteus medius activity affects the golf swing, but this muscle has been well-documented as an active pelvic stabiliser. ${ }^{[8]}$ The primary aim of this study was to assess the effect of the KT on the gluteus medius muscle on hip 
abduction strength. The secondary aim was to determine whether a correlation exists between hip abduction strength and the $\mathrm{x}$-factor, ball distance and accuracy.

\section{Methods}

Twenty-nine registered students from a golf facility gave informed consent to participate in this study. Male golfers with a Golf Association handicap of scratch \pm 2 and between 18- and 25-years old were included. Golfers with a history of previous trauma or severe injury, including fractures, vertebral joint or disc injuries, or suffering from a current injury, were excluded from the study.

Participants were randomised according to those who would be wearing the KT and those who would not use the KT on the first test day. The converse occurred on the second test day. Each participant carried out a standardised five-minute warm-up routine, consistent with their academy's warm-up protocol, followed by five warm-up golf swings with their own driver. There are certain characteristics of a driver that affects ball flight distance and accuracy, including shaft stiffness, shaft length and club face loft. ${ }^{[3]}$ This would not affect
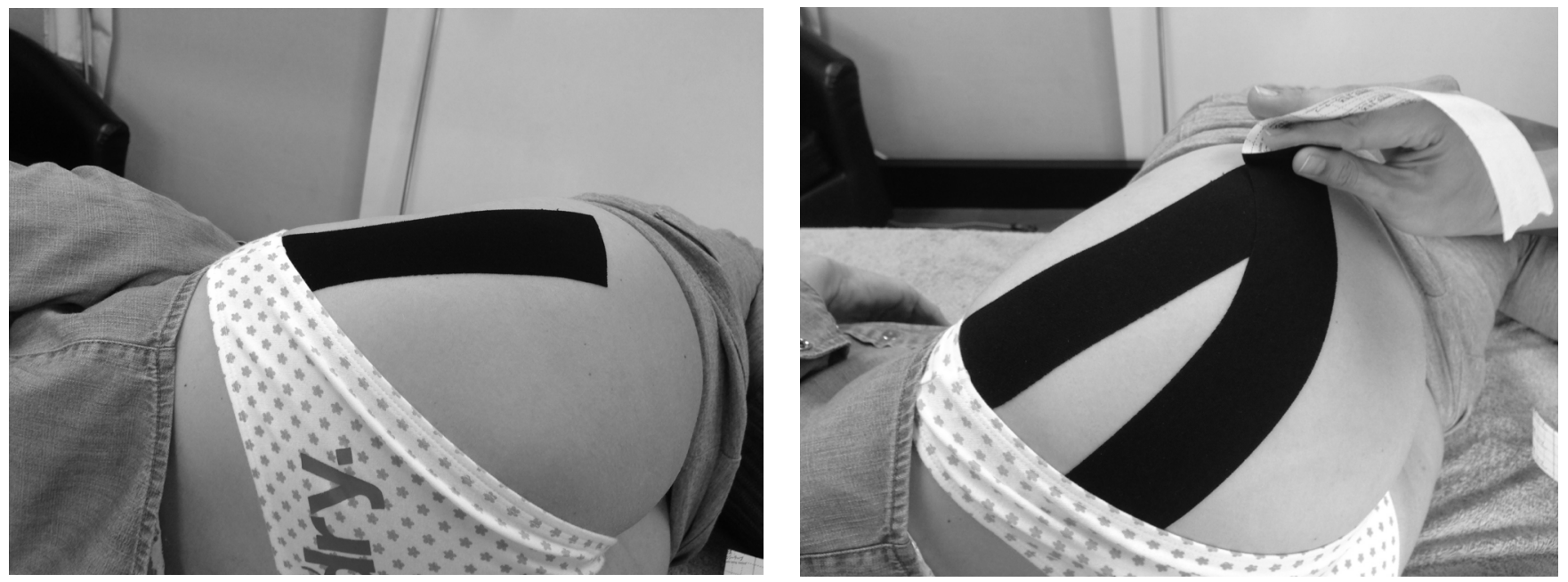

Fig. 1. Kinesio-taping of the gluteus medius muscle

The test was conducted over a period of two days. The procedure was identical for both groups. The non-tape group would have their strength test without the KT and thereafter the swing test would be conducted. On the following test day they would have their strength test with the KT applied and thereafter their swing test would be conducted, and vice versa. The isometric hip abduction strength test was carried out on the participant's dominant gluteus medius muscle (corresponding to the trail leg in the golf address position) with a MicroFET handheld Dynamometer (Hogan Industries, Draper, UT) by the researcher. Kolber et al. ${ }^{[15]}$ concluded that handheld dynamometry is reliable for measuring muscle strength (ICC 0.971-0.972). The average of three force tests was calculated. The participant was placed in the side-lying position, with the dominant hip in neutral rotation and slight extension, and was asked to abduct the hip to approximately $30^{\circ}$. The researcher stabilised the pelvis with one hand and applied medially directed resistance with the dynamometer in the other hand, just proximal to the greater trochanter of the femur. ${ }^{[16]}$ this one group pretest-posttest quasi-experimental study as each participant's data with the KT was compared to the same participant's data without the KT, using the same driver in both instances. This warm-up was done prior to hip abduction strength testing and the KT application.

The KT application was standardised and the research assistant applied it in exactly the same way on each participant (Fig. 1). ${ }^{[14]}$ Two "I" strips of tape were used and applied proximal to distal. The first strip was applied with the participant in the side-lying position with the dominant hip on top and in adduction. This strip was anchored, without tension, to the lateral lip of the iliac crest, lateral to the anterior superior iliac spine. The tape was activated at proximal anchor point and laid over the gluteus medius with slight tension due to the adduction of the hip. The tape was anchored distal to the greater trochanter laterally. The second "I" strip was anchored to the iliac crest lateral to the posterior superior iliac spine. The hip was placed in flexion and adduction. The distal anchor point was the skin over the lateral greater trochanter.

(hotion SysteM (BMS), created and manufactured by (iClub ${ }^{T M}$ Inc., Florida, USA) was used to analyse the body angles and speeds of activity of each participant's golf swing, to obtain information relating to the $\mathrm{x}$-factor, shoulder and hip rotation angles and speeds. Each participant, in turn, was fitted with the Body Motion System vest which was adjusted to fit the participant's body. The participant stood on the pre-marked testing area in front of the golf driving range. The participant carried out ten shots off an artificial turf tee box. The same standard range ball brand was used by each participant. Each participant used his own driver to represent the swing and ball flights experienced while playing. FlightScope ${ }^{\oplus}$, created by EDH, Ltd., South Africa, is a Tracking Golf Radar that accurately measures ball flight and club tracking. Information gathered by the FlightScope ${ }^{\circledast}$ includes club head speed, ball speed, smash factor ratio (accuracy) and ball distance. The swing point of interest for the $\mathrm{x}$-factor calculation was calculated as the difference between the upper torso rotation angle and the pelvic rotation angle at the top of the backswing. ${ }^{[3]}$ The main focus was on the point of ball 
contact, in order to measure club head speed and ball speed, and ball landing distance.

The data gathered in the taped and non-taped groups were analysed using a paired Student's t-test, when testing at the 0.05 level of significance. Effect sizes were calculated using Cohen's $d$ where effect sizes of $0.2,0.5$ and 0.8 were interpreted as small, medium and large, respectively. Correlation between gluteus medius and the $\mathrm{x}$-factor, ball flight distance and accuracy, with and without the KT application, was done using the Pearson correlation analysis.

Ethical approval was granted by the Human Research Ethics Committee of the associated tertiary institution (reference number M10536).

\section{Results}

Table 1 summarises the mean values with respect to the outcome measures investigated, including hip abduction strength, the $\mathrm{x}$-factor, ball flight distance and smash ratio (accuracy), with and without KT application. The strength of hip abduction was increased when KT was applied to the muscle $(\mathrm{p}<0.001)$, with a small effect size (Cohen's $d$ ) of 0.24 . KT application did not have a significant effect on the $\mathrm{x}$-factor $(\mathrm{p}=0.28)$, ball flight distance $(\mathrm{p}=0.53)$ and accuracy $(\mathrm{p}=0.1)$, despite the increase in hip abduction strength. Furthermore, no meaningful relationship could be established between hip abduction strength and the biomechanical variables (x-factor, ball flight distance and smash ratio), with and without the KT (Table 2).

Table 1. Comparison of mean variables with and without the KT $(n=29)$

\begin{tabular}{|c|c|c|c|c|c|c|}
\hline Variable & $\begin{array}{l}\text { Mean }( \pm S D) \\
\text { without KT }\end{array}$ & $\begin{array}{l}\text { Mean }( \pm S D) \\
\text { with KT }\end{array}$ & $\begin{array}{l}\text { Mean }( \pm S D) \\
\text { Difference }\end{array}$ & $\begin{array}{l}\text { Confidence } \\
\text { interval }\end{array}$ & p-value & $\begin{array}{l}\text { Effect size } \\
(\text { Cohen's } d)\end{array}$ \\
\hline Hip abduction strength $(\mathrm{N})$ & $234( \pm 41)$ & $244( \pm 39)$ & $-10( \pm 14.7)$ & -15 to -4 & $<0.001^{\star}$ & 0.24 \\
\hline $\mathrm{X}$-factor $\left({ }^{\circ}\right)$ & $57( \pm 10)$ & $59( \pm 8)$ & $-1( \pm 6)$ & -4 to 1 & 0.28 & 0.14 \\
\hline Ball flight distance (m) & $269.5( \pm 15.1)$ & $268.5( \pm 16.9)$ & $1.0( \pm 8.7)$ & -2.3 to 4.3 & 0.53 & 0.06 \\
\hline Accuracy (smash factor ratio) & $11.43( \pm 0.03)$ & $1.42( \pm 0.03)$ & $0.01( \pm 0.03)$ & -0.002 to 0.21 & 0.10 & 0.33 \\
\hline
\end{tabular}

Table 2. Relationship between gluteus medius strength, and the variables with and without the $\mathrm{KT}(\mathrm{n}=29)$

\begin{tabular}{lllll}
\hline Variable & $\begin{array}{l}\text { r-value } \\
\text { without KT }\end{array}$ & $\begin{array}{l}\text { p-value } \\
\text { without KT }\end{array}$ & $\begin{array}{l}\text { r-value } \\
\text { with KT }\end{array}$ & $\begin{array}{l}\text { p-value } \\
\text { with KT }\end{array}$ \\
\hline $\begin{array}{l}\text { X-factor }\left({ }^{\circ}\right) \\
\begin{array}{l}\text { Ball flight } \\
\text { distance (m) }\end{array}\end{array}$ & -0.28 & 0.15 & -0.46 & $0.01^{*}$ \\
$\begin{array}{l}\text { Smash ratio } \\
\begin{array}{l}\text { KT=kinesio tape; }{ }^{\circ}=\text { degrees; } \mathrm{m}=\text { metres } \\
{ }^{*} \text { Level of significance is set at } \mathrm{p}<0.05\end{array}\end{array}$ & 0.66 & -0.03 & 0.90 \\
\end{tabular}

\section{Discussion}

Hip abduction strength improved with the application of the KT, although the effect size was small. A reason for this improvement could be that taping a muscle may augment the pull of the fascia on the muscle which would be effective in enhancing sufficient force on this muscle to create a positive change. ${ }^{[14,17]}$ This could confirm that the KT application has an effect on the smooth muscle cells within the fascia, facilitating them to contract, without hampering range of motion. Another possible mechanism for improvement of force production could be KT's effect on the neural pathways by stimulation of afferent neural receptors. The KT's ability to re-educate the neuromuscular system was corroborated in a study conducted on the effects of taping on scapular kinematics and muscle strength. ${ }^{[18]}$ The results in this study showed that taping was successful in creating positive changes in scapular motion and muscle strength.

According to the hypothesis for the present study, participants who improved most in their hip abduction strength after the KT application should also have shown a concurrent improvement in the other variables tested, namely, the $\mathrm{x}$-factor, ball flight distance and accuracy. However, this was not shown in this study. This finding could be due to the individuality among the participants, each having their own unique style of coordinating the golf swing components. Applying the KT to a participant's pelvis may adversely alter the usual pelvic mechanics. This result may change if the participant practices with the tape application over a period of time, in order to get used to the muscle facilitation created by the tape.

Another reason for the lack of improvement in the $\mathrm{x}$-factor could be that despite the improvement in strength in one muscle, may not necessarily lead to an improvement in the golf swing as a whole, as many muscles act in unison to create the golf swing. ${ }^{[5]}$ Stretching the hip and trunk maximises the $\mathrm{x}$-factor produced. If any one of the hip and pelvic stabilising muscles are weak, such as the gluteal muscles, the hip adductors or lateral rotators or the pelvic stabilisers as a whole, the pelvis would not remain still and will rotate with the torso and shoulder girdles, thereby diminishing the $\mathrm{x}$-factor. ${ }^{[3]}$ Other than the gluteus medius, specific pelvic stabilisers, such as the gluteus maximus with its greater volume, or the short external rotators with their large physiological cross-sectional area and short fibres, may play a greater role in pelvic stability and the $\mathrm{x}$-factor, by storing potential energy and developing power for the downswing. ${ }^{[19]}$ A lack of trunk rotation range of motion, altered internal or external rotation of the hips, decreased shoulder girdle movement and upper torso dissociation control, or all of the above, may also adversely affect the $\mathrm{x}$-factor.

The results showed no meaningful relationship between hip abduction strength, the $\mathrm{x}$-factor, ball flight distance and accuracy. These are, however, not the only contributing factors to ball flight distance; swing speed, timing of the kinetic chain and accuracy of ball strike being equally important. ${ }^{[6,20]} \mathrm{A}$ change in any of these factors could adversely alter the ball's flight. Due to the complicated nature of the golf swing and the countless synchronised components, there 
is a very small margin of error, and many variables (rotation angles, speed of movement, weight shift, timing of ball strike, technique) that could affect the flight of the ball. ${ }^{[2]}$ The torso-pelvic separation differential, the rate at which this occurs in the backswing, and the rate of turn during the downswing, are all considered important variables in achieving further ball flight distances. ${ }^{[22]}$ Although muscle strength improvement was statistically significant, the effect size was low. Thus this result may not be clinically significant. Furthermore, hip abduction isometric strength measured in the side-lying position may not reflect the change in muscle function that may occur with weight-bearing and sports-specific tasks. According to Souza and Powers, ${ }^{[9]}$ the gluteus medius functions eccentrically to control hip adduction and internal rotation during weight-bearing. Thus a more thorough assessment of the hip during the golf swing may provide greater insight into the relationship between hip abduction strength and limited lumbo-pelvic rotation.

The application of the KT on the gluteus medius had no significant effect on the accuracy of the swing, with a mean difference of only 0.01 . A possible reason for this is that the golfers tested all have a low handicap, with their swing being considerably more efficient than golfers with a higher handicap. An efficient swing will produce a ball speed (BS) as close to one and a half times the club head speed (CHS) as possible $(\mathrm{BS} / \mathrm{CHS}=1.5)$, indicating that the ball was struck in the "sweet spot" of the club. ${ }^{[23]}$ An already efficient swing does not leave much room for improvement, as the accuracy was already excellent without any intervention. One may find a greater impact through the use of the tape in the higher handicap group, as their accuracy is less consistent and further away from the ideal ratio of 1.5. ${ }^{[23]}$ Results in this study may show that the participants improved in certain of the outcomes, but the improvements were in different parameters which were inconsistent in each of the participants. Due to the complexity of the golf swing it could be argued that an improvement in a parameter, no matter how small, could be beneficial in improving the outcome of the golf shot. ${ }^{[21]}$

The golfers participating in this study were all high-level amateurs. As this makes up only a small percentage of the general golfing population, consideration should be given to the fact that the golf swings analysed and the outcomes measured in this study may not be representative. Therefore these findings should not be extrapolated to the average golfer. Furthermore, only one muscle was targeted in this study and there are many muscles (and other factors) that impact on the golf swing. The significant difference in muscle strength may also have been due to a learning effect, as the conditions may have been familiarised by the participants. Further research should include a long-term follow-up study investigating the effect of an extensive exercise programme, including strengthening of the pelvic stabilisers, trunk rotation mobility and scapular stabilisation on the biomechanics of the golf swing. Thus not only gluteus medius strength, but also gluteus medius coordination, timing and sequencing in the golf swing should be investigated.

\section{Conclusion}

The purpose of the study was to determine the effect that the KT has on gluteus medius strength, the $\mathrm{x}$-factor in the golf swing, driving distance and accuracy of the swing. The results showed that the gluteus medius KT successfully improved the strength of hip abduction, to a limited extent. However, it did not impact significantly on the $\mathrm{x}$-factor, ball flight distance and accuracy consistently among the participants. A possible reason for this is the complexity of the golf swing and how its precision is based on many elements of the kinetic chain. The improved strength of one muscle may not be sufficiently significant to change movement throughout the kinetic chain and may be reliant on the sequential firing and timing of the many muscles involved in the golf swing.

The results of the study have shown that it may be beneficial to incorporate the use of the KT to facilitate muscle action. The customised application of the KT on each individual golfer may be more beneficial if it is used according to their specific strength requirements. Overall, current research shows that there is insufficient evidence to support the efficacy of the KT in muscle facilitation and further research is required. ${ }^{[12,13,24]}$

Clinical relevance. This study provides preliminary evidence for the efficacy of the KT applied to a specific muscle. The results showed that the gluteus medius KT successfully improved the strength of hip abduction but did not impact significantly on the $\mathrm{x}$-factor, ball flight distance and accuracy consistently among the participants. The improved strength of one muscle may not be significant enough to change movement throughout the kinetic chain due to the complexity of the golf swing and the many elements of the kinetic chain. It is thus essential to assess each golfer individually so as to highlight problematic areas in order to develop a specific training and intervention programme.

\section{Conflicts of interest and source of funding. None declared.}

Acknowledgements. All golfers who participated in this study, as well as Danny Baleson, Gavin Groves and Ian Corbett from The World of Golf.

\section{References}

1. Burden AM, Grimshaw PN, Wallace ES. Hip and shoulder rotations during the golf swing of sub-10 handicap players. J Sports Sci 1998;16:165-176. [http://dx.doi. org/10.1080/026404198366876] PMID: 9531005.

2. Blanpied P, Levins JA, Murphy E. The effects of different stretch velocities on average force of the shortening phase in the stretch-shorten cycle. J Orthop Sports Phys Ther 1995;21:345-353. [http://dx.doi.org/10.2519/jospt.1995.21.6.345] PMID: 7655478.

3. Myers J, Lephart S, Tsai YS, et al. The role of upper torso and pelvis rotation in driving performance during the golf swing. J Sports Sci 2008;26:181-188. [http://dx.doi. org/10.1080/02640410701373543] PMID: 17852693.

4. Wilk KE, Voight ML, Keirns MA, et al. Stretch-shortening drills for the upper extremities: theory and clinical application. J Orthop Sports Phys Ther 1993;17: 225-239. [http://dx.doi.org/10.2519/jospt.1993.17.5.225] PMID: 8343780.

5. McHardy A, Pollard H. Muscle activity during the golf swing. Br J Sports Med 2005;39:799-804; discussion 799-804. [http://dx.doi.org/10.1136/bjsm.2005.020271] PMID: 16244187.

6. Hume PA, Keogh J, Reid D. The role of biomechanics in maximising distance and accuracy of golf shots. Sports Med 2005;35:429-449. [http://dx.doi. org/10.2165/00007256-200535050-00005] PMID: 15896091.

7. Nesbit SM, Serrano M. Work and power analysis of the golf swing. J Sports Sci Med 2005;4:520-533. PMID: 24627666.

8. Schmitz JR, Riemann BL, Thompson T. Gluteus medius activity during isometric closed-chain hip rotation. J Sport Rehabil 2002;11:179-189.

9. Souza RM, Powers CM. Predictors of hip internal rotation during running: an evaluation of hip strength and femoral structure in women with and without patellofemoral pain. Am J Sports Med 2009;37:579-587. [http://dx.doi.org/10.1177/0363546508326711] PMID: 19098153.

10. Thelen MD, Dauber JA, Stoneman PD. The clinical efficacy of kinesio tape for shoulder pain: a randomized, double-blinded, clinical trial. J Orthop Sports Phys Ther 2008:38:389-395. [http://dx.doi.org/10.2519/jospt.2008.2791] PMID: 18591761.

11. Schleip R. Fascial plasticity - a new neurobiological explanation: part 1. J Bodyw Mov Ther 2003;7:11-19. [http://dx.doi.org/10.1016/S1360-8592(02)00067-0]

12. Kamper SJ, Henschke N. Kinesio taping for sports injuries. Br J Sports Med 2013; 47:1128-1129. [http://dx.doi.org/10.1136/bjsports-2013-093027] PMID: 24159095. 
13. Kalron A, Bar Sela S. A systematic review of the effectiveness of Kinesio Taping - fact or fashion? Eur J Phys Rehabil Med 2013;49:699-709. PMID: 23558699.

14. Kase K. Illustrated Kinesio Taping. Ken Ikai Co. Ltd: Akinori Endo; 2003:82-83.

15. Kolber MJ, Beekhuizen K, Cheng MS, Fiebert IM. The reliability of hand-held dynamometry in measuring isometric strength of the shoulder internal and external rotator musculature using a stabilization device. Physiother Theory Pract 2007;23:119-124. [http://dx.doi.org/10.1080/09593980701213032] PMID: 17530541.

16. Hollman J, Ginos BE, Kozuchowski J, et al. The relationship between knee valgus, hip muscle-strength and hip-muscle recruitment during a single-limb step-down. J Sport Rehabil 2009;18:104-117. PMID: 19321910.

17. Schleip R, Klingler W, Lehmann-Horn F. Active fascial contractility: Fascia may be able to contract in a smooth muscle-like manner and thereby influence musculoskeletal dynamics. Med Hypotheses 2005;65:273-277. [http://dx.doi. org/10.1016/j.mehy.2005.03.005] PMID: 15922099.

18. Hsu YH, Chen WY, Lin HC, et al. The effects of taping on scapular kinematics and muscle performance in baseball players with shoulder impingemen syndrome. J Electromyogr Kinesiol 2009;19:1092-1099. [http://dx.doi.org/10.1016/j. jelekin.2008.11.003] PMID: 19147374.
19. Ward SR, Winters TM, Blemker SS. The architectural design of the gluteal muscle group: implications for movement and rehabilitation. J Orthop Sports Phys Ther 2010;40:95-102. [http://dx.doi.org/10.2519/jospt.2010.3302] PMID: 20118527.

20. Fradkin AJ, Sherman CA, Finch CF. How well does club head speed correlate with golf handicaps? J Sci Med Sport 2004;7:465-472. [http://dx.doi.org/10.1016/S14402440(04)80265-2] PMID: 15712503.

21. Jagacinski RJ, Kim TH, Lavender SA. Managing the rhythmic complexity of hitting a golf ball. Journal of Mot Behav 2009;41:469-477. [http://dx.doi.org/10.3200/35-08075] PMID: 19508955.

22. Evans K, Refshauge KM, Adams RD, et al. Swing kinematics in skilled male golfers following putting practice. J Orthop Sports Phys Ther 2008;38:425-433. [http:// dx.doi.org/10.2519/jospt.2008.2617] PMID: 18591760.

23. Ishii H, Leech NA, Rotheneder R. Method and system for characterizing golf ball striking ability. Patent Application Publication: USA 2013; US 2013/0157772 A1.

24. Morris D, Jones D, Ryan H, et al. The clinical effects of Kinesio ${ }^{\circledR}$ Tex taping: A systematic review. Physiother Theory Pract 2013;29:259-270. [http://dx.doi.org/10. 3109/09593985.2012.731675] PMID: 23088702. 